\title{
CRM and Customer Portfolio Management for E-Tailers
}

by

Dennis Kundisch, Stefan Sackmann ${ }^{1}$, Markus Ruch ${ }^{1}$

February 2007

in: Proceedings of the Forty-First Annual Hawaii International Conference on System Sciences (HICSS- 41), Waikoloa, Hawaii, (USA), Januar 2008, IEEE Computer Society Press, Los Alamitos, Hawaii 2008.

\footnotetext{
${ }^{1}$ Albert-Ludwigs-Universität Freiburg, Institut für Informatik und Gesellschaft, Abteilung Telematik
} 


\title{
CRM and Customer Portfolio Management for E-Tailers
}

\author{
Dennis Kundisch ${ }^{1}$, Stefan Sackmann ${ }^{2}$, and Markus Ruch ${ }^{2}$ \\ University of Freiburg, \\ ${ }^{I}$ Department of Information Systems and \\ ${ }^{2}$ Department of Telematics \\ D-79085 Freiburg \\ dennis.kundisch@vwl.uni-freiburg.de \\ \{sackmann|ruch\}@iig.uni-freiburg.de
}

\begin{abstract}
"Don't put all your eggs in one basket" is common wisdom with respect to financial portfolio theory. The configuration of customer portfolios with regard to appropriate risk and return measures, however, is generally an accidental occurrence based on a number of separated loyalty or acquisition initiatives rather than a deliberate planning process. In this contribution, we propose to use portfolio selection theory to identify the optimal configuration of a customer portfolio. Specifically, we look at two broad customer segments: transaction- and relationship-oriented customers. E-tailers are of special interest, since the target-oriented acquisition and servicing of specific customer seems to be more easily achievable due the new means of communication. A first evaluation based on customer lifetime value is realized with a publicly accessible set of empirical data from the online-retailer CDNow.
\end{abstract}

\section{CRM and e-tailers}

Many authors, e.g. $[19,21,31,48]$ argue that the basis of a firm's profitability is its customers. Hence, to increase customer value, the building of strong customer relationships as a means of gaining competitive advantage is proposed, e.g., by [36]. This insight has led to some fundamental changes in marketing theory as well as in practice towards a customer-centric view and the emergence of Customer Relationship Management (CRM). CRM centers on the valuation, selection, acquisition, retention, and development of durable customer relationships with the objective of allocating limited resources in order to maximize the firm's value.
The empirical findings regarding acquisition and retention strategies are mixed. A rule of thumb in marketing says that maintaining an existing customer relationship is far less expensive than acquiring a new one [1]. There are quite a number of contributions that suggest focusing on existing customers, assuming a positive lifetime-profitability relationship [30, 32, 33, 43]. However, Dowling et al. question such a lifetimeprofitability relationship by analyzing customer loyalty programs and have suggested a much different examination [10]. Garbarino et al. [17] as well as Ganesan [16] have shown that a differentiated treatment of transaction-oriented (short-term) and relationshiporiented (long-term) customers with appropriate marketing tools is advisable. Reinartz et al. [34, 35] find strong evidence that transaction-oriented customers may be a very profitable segment, which should not be excluded from strategic considerations.

Since there seem to be at least two segments with different buying behavior, there may be the potential for risk diversification from a financial perspective. This potential, specifically with respect to B2C-business [7], has so far been neglected. In this contribution, so-called e-tailers are of special interest, i.e. retailers like Amazon, Dell or iTunes, who use the new opportunities of Internet for adequate relationship management [42] by establishing electronic communication channels. E-tailers can automatically vary the interaction with their customers according to their goals and customers' preferences. Furthermore, they are able to manage their customer relations in a central and objective manner and thus control the overall customer portfolio according to superordinated goals like, e.g., risk management. 
This opportunity has so far been attributed little attention. For this reason, we suggest a model based on the financial portfolio theory according to Markowitz [29] that helps in determining the optimal configuration of a customer portfolio of transaction- and relationship-oriented customers. The paper is organized as follows: the next section provides an overview of recent research in customer relationship management with regard to customer portfolio management. We then present our customer portfolio model and discuss possible action options with respect to the results for e-
Traditional customer valuation concepts concentrate on assessing individual customers [22]. Dzienziol et al. [11] also acknowledge that the investment in customer acquisition and retention should be wellbalanced, based on a CLV-consideration. However, it is not enough to evaluate customers one by one and consequently decide on acquisition and retention strategies. In a customer portfolio valuation, not only the risk within a single customer relation, but also the risk contribution of each customer to the customer portfolio should be taken into account.

Table 1. Consideration of risk in the CLV

\begin{tabular}{|c|c|c|c|c|}
\hline $\begin{array}{l}\text { Form of consideration } \\
\text { of risk in the CLV }\end{array}$ & $\begin{array}{l}\text { Selected } \\
\text { literature }\end{array}$ & Area of application & \begin{tabular}{|l|} 
Considera- \\
tion of port- \\
folio effects \\
\end{tabular} & Notes \\
\hline Discount on cash flows & {$[18,24]$} & \multirow{2}{*}{$\begin{array}{l}\text { Used for customer valuation in order } \\
\text { to decide about acquisition and further } \\
\text { investments in customer relationship }\end{array}$} & \multirow[b]{2}{*}{ No } & \multirow{2}{*}{$\begin{array}{l}\text { Typical way of how } \\
\text { CLV calculations are } \\
\text { done in practice }\end{array}$} \\
\hline $\begin{array}{l}\text { Premium on the } \\
\text { discount rate }\end{array}$ & {$[12,49]$} & & & \\
\hline $\begin{array}{l}\text { WACC as discount rate } \\
\text { based on CAPM }\end{array}$ & $\begin{array}{l}{[9,19,21} \\
23,27,28 \\
37,38]\end{array}$ & $\begin{array}{l}\text { Used for customer valuation in order } \\
\text { to decide about acquisition and further } \\
\text { investments in customer relationship }\end{array}$ & $\begin{array}{l}\text { Yes, } \\
\text { implicitly }\end{array}$ & $\begin{array}{l}\text { State-of-the-art in } \\
\text { marketing literature }\end{array}$ \\
\hline $\begin{array}{l}\text { Distribution of expect- } \\
\text { ed CLV combined with } \\
\text { Markowitz' portfolio } \\
\text { selection theory }\end{array}$ & & $\begin{array}{l}\text { Used for customer portfolio } \\
\text { optimization }\end{array}$ & $\begin{array}{l}\text { Yes, } \\
\text { explicitly }\end{array}$ & $\begin{array}{l}\text { This approach was } \\
\text { suggested by [3] with } \\
\text { respect to product } \\
\text { portfolio decisions }\end{array}$ \\
\hline
\end{tabular}

tailers. The applicability of the model is shown using a publicly accessible data set of the online retailer CDNow. Finally, the results of the paper are summarized and directions for further research are discussed.

\section{CRM and portfolio theory}

One basic condition for customer relationship management is the ability to estimate a customer's value for a firm. A customer valuation concept, compatible with the principle of shareholder value that has gained broad attention in marketing literature and CRM research is the Customer Lifetime Value (CLV). However, while marketing literature discusses the concept and relevant parameters of CLV in detail, it still lacks practicability, since the estimation of future profitability is uncertain [44]. Thus, in a non-contractual relationship between a firm and customers, which is particularly true of e-tailers selling, e.g., books or CDs on the Internet, the assumption of a deterministic world, where future cash flows are known with certainty, seems to be fairly unrealistic [27]. The consideration of risk, i.e. the deviation of cash flows from their expected value, is therefore crucial for a riskaverse decision maker.
For reasons of simplification, the ability to better predict individual customer behavior as well as strategic target group considerations, customers are often grouped into segments. These segments should be formed trying to group together customers exhibiting similar buying behavior [50]. Consequently, these segments can be addressed by specific marketing campaigns. Based on an appropriate segmentation, portfolio models on a conceptual level are proposed generally visualizing on two dimensions: an internal factor (e.g. competitiveness in the market) and an external factor (e.g. customer attractiveness) (e.g. [2]). Portfolio effects in terms of risk diversification - just like in a portfolio of financial assets - are not addressed but should be taken into account [9]. Interestingly, there are only a few contributions on this issue. For an overview of approaches considering risk in CLV calculations see Table 1 .

Incorporating risk and at the same time a portfolio view into customer valuation, some authors propose the usage of the weighted average cost of capital (WACC) of a firm - based on the capital asset pricing model (CAPM) [6] - as minimum rate of return. It is argued that the security market line may be used to adjust the specific WACC of any risky investment 
alternative and thus the beta value of a customer (segment) reflects the systematic business risk of the segment and the systematic financial risk of the firm itself [28]. Consequently, the net present value (NPV) of the customer segment is given by the expected cash flows, discounted with the segment-specific risk-adjusted WACC. However, CAPM just takes systematic risks into account, whereas it is assumed that unsystematic risk can be neglected due to perfect diversification. Moreover, defining a market portfolio with respect to customers is quite a challenging task. [37] as well as [9] define the "market portfolio" in the CRM context as the firm's current customer base. In our view, this is inadequate if a decision about changing the portfolio weights of different segments is to be taken within a growth strategy of the firm. Another shortcoming of the CAPM is the assumption of homogeneous expectations of all investors. This assumption is crucial for the existence of the market portfolio and the equilibrium on capital markets [6].

Cardozo et al. [3] suggest applying Markowitz' theory in product portfolio decisions. Although applying Markowitz' theory in a non-financial context also brings some shortcomings - which have led to an interesting discussion, see $[4,8]$ - for the problem at hand, it seems nevertheless well-suited to make customer portfolio decisions. This is discussed and argued in further detail in the next section.

\section{Model for optimizing customer portfolio}

It has been acknowledged in literature [21, 39] that customer relationships share characteristics with other business assets: They generate a risky cash flow. Thus, just like financial assets, they provide for an expected return, measured, e.g., as a CLV. Some of them provide a larger CLV but their cash flows may be unsteady and therefore more risky, whereas the CLV of others may be smaller but more stable [15]. In general, CLV is calculated as the sum of expected future cash flows based on potentially existing contracts as well as expected future transactions. These expected cash flows integrate parameters such as value and frequency of purchase as well as product category. CLV is regarded as an exogenous input into the optimization model here for two reasons: First, the model shall be kept simple in order to focus on the optimization issue. Second, since the proposed model is independent of the concrete method to calculate CLV, the chosen method does not affect its application. Compared to financial assets, however, customer relationships are more difficult to measure, there is no liquid market where they could be traded and a customer might decide to terminate a non-contractual relationship with a firm at very short notice. These issues have to be taken into account when trying to build up a model for customer portfolio optimization, something that has so far been neglected by marketing managers [39]. The portfolio selection theory according to Markowitz seems best suited for this application, since it does not make too restricting assumptions about the characteristics of the market participants, as CAPM does.

In practice, a firm needs both: an optimization of the customer portfolio [39] and at the same time an efficient management of individual customer relationships [34]. Ideally, these two issues should be simultaneously optimized. Due to the complexity, it seems appropriate to split this optimization process up into two steps: First, a firm decides on the overall customer portfolio. Here, just broad customer segments are considered. Second, the customer relationships within the (optimal) customer portfolio are managed on an as individual as possible basis. Since a lot has already been written on the second step, we will concentrate on the optimization of the overall customer portfolio in our contribution. By doing this, we start with a simple segmentation approach just distinguishing loyal, i.e. relationship-oriented customers and transaction-oriented customers, i.e. customers that do not feel committed to a firm after buying some products there. ${ }^{1}$ The application of portfolio selection theory requires a few assumptions about the customers and the characteristics of a customer relationship.

\subsection{Assumptions}

\section{(AC) Customers}

Relationship-oriented customers are customers that repeatedly buy after a successful acquisition in $t=0$ at two or more points in time $t \in\{0, \ldots, T\}$. Transactionoriented customers are customers that buy just after a successful acquisition in $t=0$ and subsequently stop buying from this e-tailer. ${ }^{2}$

\section{(ACS) Customer Segments}

There are two ex ante observable and disjunctive customer segments $i \in\{R ; S\}$ in the market: Segment $R$ comprises all relationship-oriented customers and segment $S$ comprises all transaction-oriented customers. A

\footnotetext{
1 Obviously, within these segments, there may be several sub-segments that may still vary depending on relevant parameters (e.g. value of purchase). In analogy to Markowitz' portfolio selection theory, the proposed model may be easily expanded to cope with more than two segments.

2 If the e-tailer wants to later reperform the optimization process, it follows that transaction-oriented customers have to be regained in order to make a repeated purchase. Obviously, the two defined segments are idealized in order to allow for a first simple analysis.
} 
segment $i$ yields the cash inflow $C F_{i, t}{ }^{\text {in }}$ which is the average periodic revenue per capita at time $t$, with $t \in\{0, \ldots, T\}$, as well as the average cash outflow per capita $C F_{i, t}{ }^{\text {out }}$ that consists of direct costs, i.e. costs for acquisition, service and advisory as well as transaction costs. The segments are stable over the planning horizon, i.e. there is no transaction-oriented customer that becomes a relationship-oriented one and vice versa.

\section{(ACP) Customer Portfolio}

The e-tailer has no customers in his portfolio $P F$ before $t=0$. The customer portfolio after the acquisition in $t=0$ consists of $N \in I N$ customers. The portfolio shares $r$ and $s$ of the segments $R$ and $S$ (with $r+s=1$ and $r \geq 0, s \geq 0$ ), given by the ratio of the number of customers in a segment and the total number $N$ of customers in the portfolio, are the decision variables of the portfolio optimization in $t=0$ for the whole planning horizon until $t=T^{3}$.

For each customer segment $i$, with $i \in\{R ; S\}$, the average per capita cash flow $Q_{i}$ is given by

$$
\begin{aligned}
& Q_{R}=\left(\tilde{q}_{0, R}, \tilde{q}_{1, R}, \ldots, \tilde{q}_{T, R}\right) \text { and } \\
& Q_{S}=\left(\tilde{q}_{0, S}, 0, \ldots, 0\right)
\end{aligned}
$$

The components $\tilde{q}_{t, i}$ are the average net cash flows per customer in customer segment $i$ and represent the delta of cash in and outflows at time $t \in\{0, \ldots T\}$ :

$$
\tilde{q}_{t, i}=C F_{t, i}^{\text {in }}-C F_{t, i}^{\text {out }}
$$

$\widetilde{q}_{t, i}$ are independent and identically distributed random variables, which are given at the decision time $t=0$. The average per capita CLV $C L V_{i}$ of segment $i$, which is also normalized to the number of customers in segment $i$ at $t=0$, is given by the expected NPV of $Q_{i}$ ( $z$ denotes the risk free market interest rate):

$$
\mu_{i}=E\left(C L V_{i}\right)=\sum_{t=0}^{T} \frac{E\left(\tilde{q}_{t, i}\right)}{(1+z)^{t}}
$$

For the following model, we define the expected return per capita $\mu_{i}$ of customer segment $i$ as $E(C L V i)$ at time $t=0$, as is done in equation (4). Hillier et al. [20] showed that if the net cash flows are supposed to be independent and identically distributed random variables, it may be concluded that the expected return per capita $\mu_{i}$ is asymptotically normally distributed. On

\footnotetext{
3 The planning horizon for the CLV calculation as well as for the optimization is assumed to be equal here. Of course, one may also model different planning horizons, however with the risk that the major cash inflows included in the CLV calculation may lie after the planning horizon for the optimization, leaving the decision maker potentially with an unintended result at the end of the planning horizon of the optimization.
}

the basis of assumptions ACP and ADM (see below), the expected NPV per capita of the customer portfolio $E\left(C L V_{P F}\right)$, shortly denoted as $\mu_{P F}$, may be calculated as the sum of the weighted NPV of both segments' $\mu_{i}$ :

$$
\mu_{P F}=E\left(C L V_{P F}\right)=r \cdot \mu_{R}+s \cdot \mu_{S}
$$

\section{(ACA) Customer Acquisition}

Customers can be acquired only at $t=0$. The customer segments are large enough and the e-tailer is comparably small enough so that there will never be a shortage of acquirable customers in a customer segment.

\section{(ADM) Decision Maker}

The risk-averse decision maker aims to maximize the utility per capita of the portfolio alternatives. The risk ${ }^{4}$ of the expected return per capita of segment $i$ is quantified by the standard deviation $\sigma_{i}=\sqrt{\operatorname{Var}\left(C L V_{i}\right)}$.

The risk $\sigma_{P F}$ of the expected portfolio return per capita involves the standard deviation $\sigma_{i}$ of the portfolio segments as well as their covariance $\operatorname{Cov}_{R S}$, i.e. $\sigma_{P F}=\sqrt{r^{2} \sigma_{R}^{2}+s^{2} \sigma_{S}^{2}+2 r S C o v_{R S}}=\sqrt{r^{2} \sigma_{R}^{2}+s^{2} \sigma_{S}^{2}+2 r \sigma_{R} s \sigma_{S} \rho_{R S}}$. The correlation coefficient $\rho_{R S}<1$ is given in time period $t=0$ and is constant over the planning horizon. For all possible values $x$ assumed by the random variable $C L V_{P F}$, their utility is given by $u(x)=1-e^{-a x}$. The parameter $a$ denotes the Arrow-Pratt measure that indicates the individual level of risk aversion ${ }^{5}$.

Schneeweiß [41] showed that the only rational preference relation that meets assumption ADM, i.e. in case of normally distributed random variables, the utility function given in (ADM) and compatibility with the Bernoulli-Principle, is given by the following equation:

$$
\max \Phi_{u}\left(\mu_{P F}, \sigma_{P F}\right)=\mu_{P F}-\frac{a}{2} \sigma_{P F}^{2}=U_{P F}
$$

The parameters $\mu_{P F}$ and $\sigma_{P F}$ both depend on the portfolio shares $r$ and $s$ of the two customer segments, which have to be chosen so that $\Phi_{u}\left(\mu_{P F}, \sigma_{P F}\right)$ is maximized. In the context of relationship valuation, $a / 2$ is defined as a monetary factor that reflects the price per unit of risk, i.e. the reward asked by a risk-averse decision maker for carrying the risk $\sigma_{P F}$. Since the portfolio shares of the two customer segments sum up to one, the expected portfolio utility $U_{P F}$ is a monetary per capita amount.

\footnotetext{
4 Risk includes both systematic risks (e.g. macroeconomic shocks, competitive environment) as well as unsystematic risks (e.g. product and pricing strategies of the e-tailer).

5 For risk-averse decision maker: $a>0$; for risk-neutral decision maker $a=0$.
} 


\subsection{Portfolio optimization and options for action}

For the optimization, firstly $\mu_{P F}$ and $\sigma_{P F}$ of all efficient portfolio alternatives have to be derived, i.e. the so-called efficient frontier (EF) is calculated, and secondly, the optimal portfolio based on the utility function provided in assumption (ADM) can be determined using equation (5).

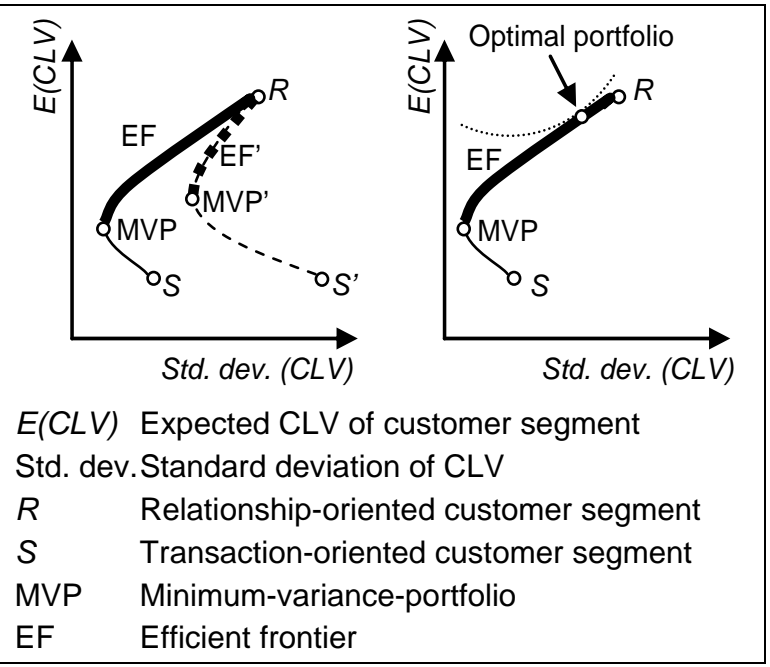

Figure 1. Efficient frontier with two customer segments

Generally, the decision maker has to choose between portfolios with higher expected return accompanied by higher variance and portfolios with lower expected return and variance. Furthermore, he will only select a portfolio $P F$, which meets the following conditions and is therefore referred to as efficient [29]:

- The portfolio $P F$ is a feasible portfolio, i.e. all portfolio weights are part of the feasible interval of $r, s \in[0 ; 1]$ and the portfolio shares sum up to one.

- If any feasible portfolio has a greater expected return, it must also have a greater variance of return than the portfolio $P F$.

- If any feasible portfolio has a smaller variance of return, it must also have a smaller expected return than the portfolio $P F$.

Analytically, this may be written as:

$$
\min _{r} \sigma_{P F}^{2}=r^{2} \cdot \sigma_{R}^{2}+s^{2} \cdot \sigma_{S}^{2}+2 r s \rho_{R S} \sigma_{R} \sigma_{S}
$$

The objective function (6) has to be minimized subject to the following constraints:

$$
\begin{aligned}
& \bar{\mu}_{P F}=r \cdot \mu_{R}+s \cdot \mu_{S}(\text { see equation }(4)) \\
& r \geq 0, s \geq 0(\operatorname{see}(\mathrm{ACP})) \\
& r+s=1(\operatorname{see}(\mathrm{ACP}))
\end{aligned}
$$

Talking about the EF, one might think that with just two risky assets, there may be four different cases to be differentiated, where relationship-oriented customers $R$ have a lower or higher return and at the same time a lower or higher risk compared to transaction-oriented customers $S$. From portfolio selection theory, we know that the set of efficient portfolios, where for a given level of risk no other investment opportunity offers a higher return, form the EF (see above). Generally, the $\mathrm{EF}$ in a no-short-sales setting corresponds to a concave curve in a risk-return-diagram starting at the minimumvariance-portfolio (MVP) and ending at the asset with the highest return (see bold line on the left hand side of Figure 1). In the special cases where $\rho_{R S}=1$ or $\rho_{R S}=-1$, the EF is a straight line.

In the financial markets, higher risk is generally associated with a higher return. Obviously, this need not be true if the "assets" are customers - an issue that deserves more thought in future research. However, even though the individual asset $R$ dominates asset $S$ ' (see left hand side of Figure 1), i.e. $R$ offers a higher return for less(!) risk due to a sufficiently small correlation coefficient, it can turn out that a mixture of these two assets is still superior in comparison to a full investment in asset $R$ - of course depending on the risk preferences of the decision maker. If the correlation coefficient is sufficiently high and the segment with the higher return carries sufficiently lower risk compared to the other segment, the EF is just the point $R$.

Remarkably, all possible mixtures of the two customer segments within the customer portfolio lie on the line that connects $R$ and $S$. Since the optimal portfolio has to be efficient, the point of tangency of the indifference curve (dotted line on the right hand side of Figure 1) and the EF, i.e. the point where the slopes of both functions are equal, represents the locus of the optimal portfolio at the given risk preference. Thus, after the EF has been determined, equation (5) may be used to determine the preferred customer portfolio weights. Finally, we may check if the utility per capita of the optimal portfolio covers the average NPV of direct and indirect fixed costs per capita.

Once the position on the EF has been determined and the risk preferences of management are clear, there are basically three action options that can be pursued. First, the position on the EF can be altered by specific acquisition efforts in the next period. E-tailers may use their personalization efforts and targeted market campaigns to attract customers to the segment where they have a shortage. One has to bear in mind here that existing customers generally cannot be "sold" at the market and - at least for reasons of image - should not be 
got rid of in any other way. Therefore, it may occur that the overall customer portfolio can only be adapted to the actual risk preferences gradually over time, since budget restrictions will not allow the acquisition of an arbitrary amount of customers of one specific segment.

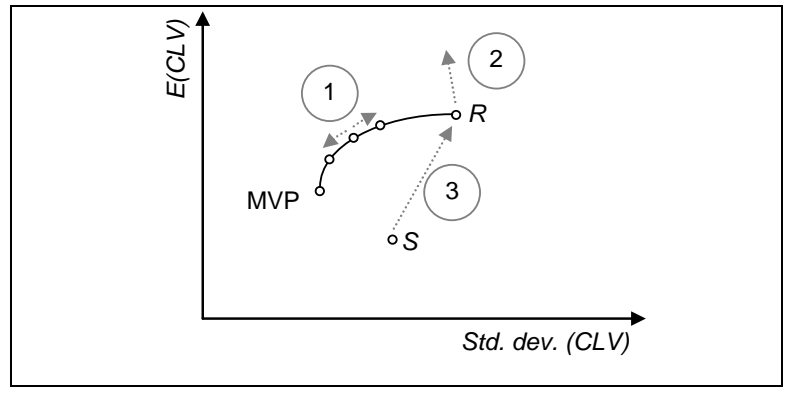

Figure 2. Action options

Second, investments in customer relationships, loyalty programs and further measures can be used in order to increase the expected CLV per capita of segment $R$. In general, there will be a difference between the expected CLV after the acquisition of a (potentially) loyal customer and the full CLV potential of this customer. As long as it is economically sound to do so, this potential should be realized. Doing so moves the point $R$ in the $\mu$ - $\sigma$-diagram upwards and potentially also to the left. This, in turn, alters the EF. Hence, a new optimal position on the EF can be determined. This constitutes a major difference between financial markets and the "market of customers": While the return and volatility estimations of financial assets (e.g. stocks) are an exogenous input to the Markowitz model, CLV and its standard deviation are far from being given [4, 8]. In contrast, these are the parameters companies are trying hard to improve. A huge body of literature specifically deals with models to improve the accuracy of CLV as well as with measures to increase it and to lower the risk of churning. Suggested measures include:

- Introduction of loyalty programs or customer clubs often associated with customer cards (an example are frequent flyer programs of all major airlines).

- Service-related measures: e.g. preferred service for existing customers or professional complaint management.

- Price-related measures: e.g. discounts or kick-back payments.

- Product-related measures: e.g. using data mining techniques to determine the next product to buy [25].

- Communication-related measures: e.g. apologies, explanations, additional information, arguments of benefits [42].

Particularly for e-tailers, the Internet offers possibilities to combine these more traditional marketing instru- ments (product, price, place, promotion) with precision, payment, personalization, and push and pull [5].

Third, short-term, transaction-oriented customers may be turned into loyal customers, increasing the share of segment $R$ and decreasing the relative weight of segment $S$. Transaction-oriented customers were for the sake of simplicity - defined as those leaving the firm after a purchase in the period of the acquisition (see (AC)). However, in practice this need not be true. Moreover, there may be customers that just have to be activated somehow in order to become loyal partners of the firm. In this case, the EF does not change, but the position on the frontier is altered. Measures to achieve such a switch between segments include the same as those named above for the increase of CLV.

In Figure 2, the three action options are depicted. Obviously, these options are not mutually exclusive but should be simultaneously considered and optimized. There are a number of contributions that each deal with one of these three steps. The art of successful CRM, however, integrates these (at least) three aspects in order to generate an optimal investment or marketing plan. This issue is definitely subject to further research.

With these preliminary results, some limitations of the presented model should be noted. Obviously this is a simple model with just two segments and a one-period optimization. Even though current data-warehousing and data-mining techniques are already very powerful, the parameter estimation, particularly with regard to the correlation coefficient, is a challenge. The segments are defined as idealized representations of customers in real life and it is assumed that with targeted marketing efforts, it is possible to acquire the "right" customers. This may have become easier for etailers compared to traditional retail outlets, since much more computing power as well as data about (potential) customers are available and can be processed. In addition, individualization and personalization is achievable at acceptable costs on the Internet. Nevertheless, there is still a long way to go until such targeted and successful marketing campaigns are in place. Moreover, although the application of the model is independent of the method used to calculate CLV, the actual results of the optimization may vary considerably depending on the chosen method. Considering all the limitations mentioned above, results of the analysis have to be handled with care. Besides these limitations, Markowitz' portfolio selection theory still gets by with much less restrictive assumptions compared to CAPM proposed in many other contributions (see above). 


\subsection{First evaluation with an e-tailer's data set}

For a better clarification of the model, the optimization of a customer portfolio will be performed by using a publicly available, exemplary data set from the online retailer $\mathrm{CDNow}^{6}$. The data set contains 2,357 customers, who made their first purchases of at the CDNowwebsite in the first quarter of 1997 and were observed over a period of 39 weeks $^{7}$. . The sold products are CDs and the relationship between customers and retailer is non-contractual. In total, 1,411 customers bought only once and 946 up to 30 times.

In section 3.3.1, the Pareto/NBD-Model is applied as method for segmenting the overall customer portfolio into the aspired segments of relationship- and transaction-oriented customers ( $R$ and $S$ ). Subsequently, based on the segments' CLVs and their respective standard deviations, the EF is determined in section 3.3.2. Certainly, ex post data is analyzed here, whereas an optimization should take place prior to taking new acquisition measures using estimations for the parameters. However, analyzing past data will often be one useful source for obtaining these estimations.
Pareto/NBD-Model from [40] - particularly suitable for the analysis of situations with non-contractual customer relationships - is used. The model generates a probability $P$ (alive) $\in[0,1]$ per customer revealing whether a customer is still active or not. For calculating $P$ (alive), the exogenous variables are the total number of purchases in the observation period, the date of the last purchase and the time of the customer relationship, which are all given in CDNow data set.

Deviating from assumptions (AC) and (ACP), the empirical data set contains a continuous observation on a daily basis. For simplification, the acquisition period (first 13 weeks) is merged into one single point in time named asy $t_{0}$ in the model. After calculating $P$ (alive) for every customer, a cutoff value $c$ has to be defined that separates according to their activity relationshipfrom transaction-oriented customers. In literature, a value of 0.5 is often proposed as adequate value to differentiate "alive" and "not alive" customers but [26] indicates that no standard cutoff value for $P$ (alive) exists and a sensitivity analysis with differrent $c$-values can lead to better results. Figure 3 suggests using $c=$ 0.21 as the value to divide the two customer segments. ${ }^{8}$

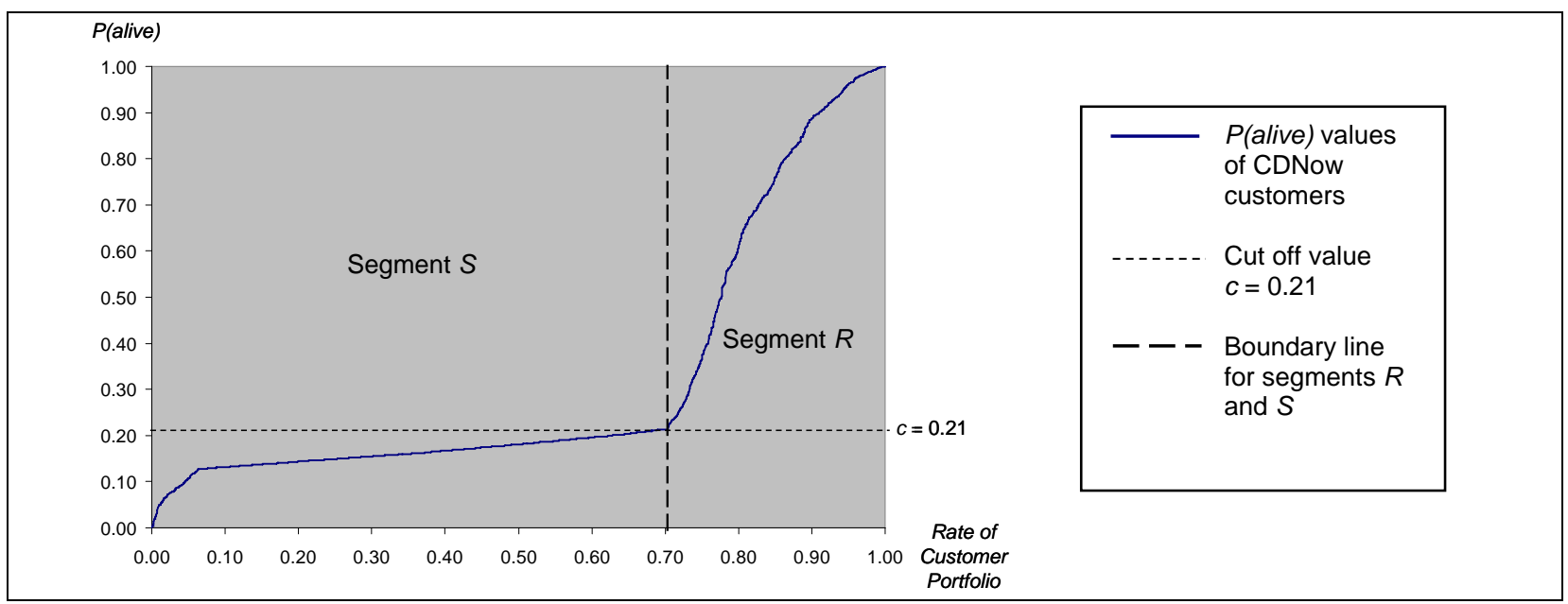

Figure 3. Segmentation of the CDNow customer portfolio

\subsubsection{Segmentation of the customer portfolio}

The first step in optimizing a customer portfolio from a risk management perspective is to differentiate between relationship- and transaction-oriented customer groups. In doing this for the CDNow data set, the

6 The data set is available at http://brucehardie.com/notes/004/. For further details of the data set see $[13,14]$

7 Although this looks more like a short-term optimization this might not be suboptimal as [47] indicate.
Customers with $P($ alive) higher c represent the relationship-oriented segment $R$ and those with a lower $P($ alive)-value - who bought only once or after several times initially nothing more for the rest of the observation period - the transaction-oriented segment $S$.

\footnotetext{
8 Using a value of 0.5 does not change the general results of the following evaluation.
} 


\subsubsection{Valuating the customer segments}

The base for the average per capita CLV $C L V_{i}$ of segment $i$ are the individual CLVs of the customers. To calculate these and to get the NPV, it is necessary to know the exact purchasing dates so that the values can be discounted to $t_{0}$. Unfortunately, this information is not included in the data set of CDNow, so the required purchasing dates are modeled by using random numbers following an equal distribution. An average cash flow per purchase has also been defined and was normalized to 1 . This enables a simple calculation of the CLVs by summing up the number of purchases per quarter and discounting these to $t_{0}$ with an assumed risk-free interest rate $z$ of $1 \%$ per quarter. To operate the portfolio optimization, simply an average CLV for each customer segment is needed together with the standard deviation. The results for the CDNow data set are shown in Table 2. Apparently, at least for this data set, higher return goes hand in hand with higher risk.

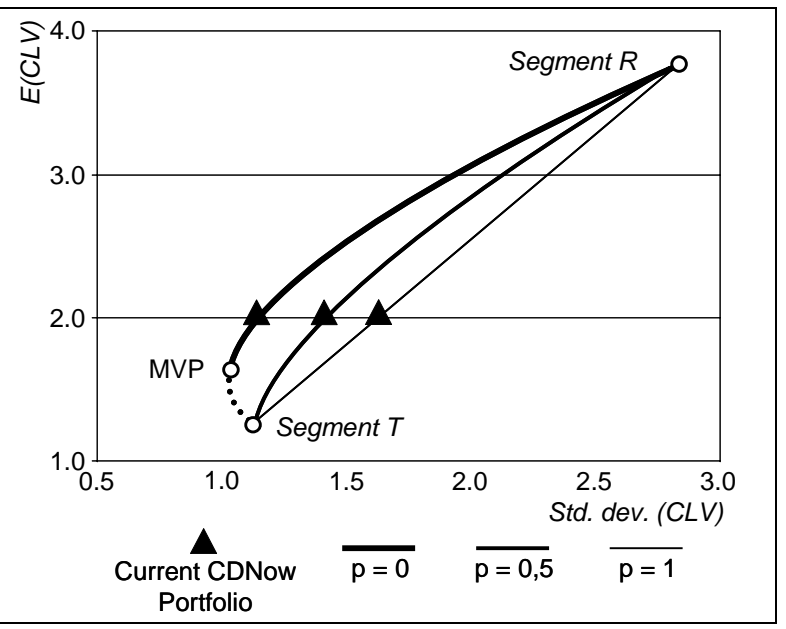

Figure 4. Alternative efficient frontiers for CDNow data set

Figure 4 shows alternative EFs for three assumed correlation coefficients for the two segments: $p=0$ (assuming stochastic independence), $p=0.5$ (assuming a positive correlation), $p=1$ (assuming a perfect positive correlation). As expected, the risk diversification potential is higher, the smaller the correlation of the expected CLV distribution of these two segments is. Assuming independence of the CLV development of the two segments $(p=0)$, the MVP is characterized by a CLV of 1.6 and a standard deviation of 1.0. In this MVP, $86 \%$ of the customers are transaction-oriented and $14 \%$ are relationship-oriented. Thus, even extremely risk-averse decision makers would choose a portfolio consisting of shares of both segments instead of just addressing transaction-oriented customers.
Table 2. Characteristics of CDNow customer segments $R$ and $S$

\begin{tabular}{|c|c|c|c|}
\hline Segment & $\begin{array}{c}\text { Number of } \\
\text { customers }\end{array}$ & $\begin{array}{c}\text { Average } \\
C L V_{i}\end{array}$ & $\begin{array}{c}\text { Standard devia- } \\
\text { tion of } C L V_{i}\end{array}$ \\
\hline$R$ & $698(30 \%)$ & 3.8 & 2.8 \\
\hline$S$ & $1,659(70 \%)$ & 1.3 & 1.1 \\
\hline
\end{tabular}

The current situation for the data set of CDNow is depicted by the triangles in the figure. The expected CLV per capita of the portfolio is 2.0. If the portfolio construction was a deliberately managed process at CDNow, this would imply a quite risk-averse management. Otherwise, the result may suggest that CDNow rethinks their customer acquisition and retention strategy in the future; given similar customer behavior.

\section{Conclusion and Outlook}

After years of proposing a focus on turning customers into loyal customers, it seems that in the last couple of years a more differentiated view has made its way in literature as well as in practice. Recent studies suggest that disloyal, transaction-oriented customers that do not expect and ask for bonus programs or other forms of customer loyalty measures may still constitute a quite profitable customer segment in the overall customer portfolio of an e-tailer. Acknowledging these issues, new questions arise - if management is considered as being risk-averse - concerning the appropriate mix of two or more customer segments with different buying behavior. Traditional customer evaluation methods mostly focus on evaluating customers one by one. Including risk into this consideration most often comes as a mere premium on the risk free discount rate for the CLV calculation. We propose a different approach in this contribution that - independent of a concrete method for CLV calculation - facilitates a complementary optimization from a risk-return perspective.

With regard to customers as assets, we transfer and apply financial theory, particularly portfolio selection theory according to Markowitz, to the issue of customer portfolio optimization. With our novel model, it is possible to account for different buying behavior of two (or potentially more) customer segments while having an integrated view on return (CLV) and risk (here measured as the standard deviation of the CLV within a customer segment). In a quite simple analysis, just looking at relationship-oriented and transactionoriented customers, it turns out that an optimal mix of these two customer segments within a customer portfolio will typically include shares of both segments. Hence, focusing just on (potentially) loyal customers 
may be optimal with respect to the expected CLV, but not necessarily with respect to the overall expected utility of a customer portfolio, incorporating the risk of future cash flows. Moreover, three action options were discussed for e-tailers based on the results of the analysis and we showed the applicability of our model using a publicly available data set of the e-tailer CDNow.

The results of the analysis contribute to the understanding of customer portfolio management and optimization. It may facilitate decision-making concerning the allocation of marketing budget for customer acquisition. At present, designing marketing measures to address specific customers segments may be feasible, in particular for e-tailers operating primarily on the Internet. However, current technological development fundamentally also extends these opportunities to stationary retail $[45,46]$.

Customer portfolio optimization and management are interesting and demanding issues for research as well as practice. There are still a lot of open research questions in these areas. Based on this contribution, we identified four major topics for future steps: First, an empirical investigation with an e-tailer going beyond the limited data set of CDNow is envisaged. Second, the presented model should be expanded to incorporate an arbitrary number of segments and issues, such as customer retention rate, frequency and value of purchases, and different product categories should be included. Third, the issue of managing customer relationships in order to increase the expected CLV and decrease the risk of churning on the one hand has to be formally combined with a simultaneous optimization of the overall customer portfolio. Fourth, the dynamic character of customer portfolio management as an ongoing process should be incorporated in the model.

\section{References}

[1] G. Bitran and S. Mondschein, "A Comparative Analysis of Decision Making Procedures in the Catalog Sales Industry", European Management Journal, Vol. 15 (2), 1997, pp. 105-116.

[2] N. Campbell and Cunningham M., "Customer Analysis for Strategy Development", Industrial Markets Strategic Management Journal, Vol. 4 (4), 1983, pp. 369-380.

[3] R. N. Cardozo and D. Smith, "Applying Financial Portfolio Theory to Product Portfolio Decisions: An Empirical Study”, Journ. of Marketing, Vol. 47 (2), 1983, pp. 110-119.

[4] R. N. Cardozo, and D. Smith, "On the Use of Financial Portfolio Theory in Marketing Decisions: A Reply to Devinney, Stewart, and Shocker", Journal of Marketing, Vol. 49 (4), 1985, pp. 113-115.
[5] C. Y. Chen, "The comparison of structure differences between internet marketing and traditional marketing", International Journal of Management and Enterprise, Vol. 3 (4), 2006, pp. 397-417.

[6] Copeland, T., J. Weston, and K. Shastri, Financial Theory and Corporate Policy, $4^{\text {th }}$ edition, Pearson Addison Wesley, Boston, Massachusetts, 2005.

[7] Cornelsen, J., Kundenwertanalysen im Beziehungsmarketing, Gesellschaft für innovatives Marketing, Nürnberg, Germany, 2000.

[8] T. M. Devinney, D.W. Stewart, and A. D. Shocker, "A Note on the Application of Portfolio Theory: A Comment on Cardozo and Smith", Journal of Marketing, Vol. 49 (4), 1985, pp. 107-112.

[9] R. Dhar and R. Glazer, "Hedging Customers", Harvard Business Review, Vol. 81 (5), 2003, pp. 86-92.

[10] G. R. Dowling and M. Uncles, "Do Customer Loyalty Programs Really Work?", Sloan Management Review, Vol. 38 (4), 1997, p. 71-82.

[11] J. Dzienziol, N. Kreyer, and N. Schroeder, "Optimierung kundenspezifischer Investitionen: Eine integrierte Betrachtung von Neukundenakquisition und Kundenwertsteigerung“, Discussion Paper, WI-147, University of Augsburg, Augsburg, Germany, 2004.

[12] Eberling, G., Kundenwertmanagement. Konzept zur wertorientierten Analyse und Gestaltung von Kundenbeziehungen, DUV, Wiesbaden, Germany, 2002.

[13] P. S. Fader and B. G. S. Hardie, "Forecasting Repeat Sales at CDNOW: A Case Study", Interfaces, Vol. 31 (2), 2001, pp. 94-107.

[14] P. S. Fader, B. G. S. Hardie, and K. L. Lee, "Counting Your Customers the Easy Way: An Alternative to the Pareto/NBD Model”, Marketing Science, Vol. 24 (2), 2005, pp. 275-284.

[15] Ford, D., L. E. Gadder, H. Hakansson, and I. Snehota, Managing Business Relationships, $2^{\text {nd }}$, John Wiley \& Sons, West Sussex, England, 2003.

[16] S. Ganesan, "Determinants of Long-Term Orientation in Buyer-Seller Relationships", Journal of Marketing, Vol. 58 (2), 1994, pp. 1-19.

[17] E. Garbarino and M. S. Johnson, “The Different Roles of Satisfaction, Trust, and Commitment in Customer Relations", Journal of Marketing, Vol. 63 (2). 1999, pp. 70-78.

[18] S. Gupta and D. Lehmann, "Customers as Assets", Journal of Interactive Marketing, Vol. 17 (1), 2003, pp. 9-24.

[19] S. Gupta, D. Lehmann, and J. Stuart, "Valuing Customers", Journal of Marketing Research, Vol. 41 (11), 2004, pp. 7-18. 
[20] F. S. Hillier and D. V. Heebink, "Evaluating Risky Capital Investments", California Management Review, Vol. 8 (2), 1965, pp. 71-80.

[21] J. Hogan, D. Lehmann, M. Merino, R. Srivastava, J. Thomas, and P. Verhoef, "Linking Customer Assets to Financial Performance", Journal of Service Research, Vol. 5 (1), 2002, pp. 26-38.

[22] J. Hogan, K. Lemon, and B. Libai, "What is the True Value of a Lost Customer?", Journal of Service Research, Vol. 5 (3), 2003, pp. 196-208.

[23] G. Hopkinson and C. Lum, "Valuing customer relationships: Using the capital asset pricing model (CAPM) to corporate relationship risk", Journal of Targeting, Measurement and Analysis for Marketing, Vol. 10 (3), 2002, pp. 220-232.

[24] D. Jain and S. Singh, "Customer Lifetime Research in Marketing: Review and Future Directions", Journal of Interactive Marketing, Vol. 16 (2), pp. 34-46.

[25] A. Knott, A. Hayes, and S. Neslin, "Next-product-to-buy models for cross-selling applications", Journal of Interactive Marketing, Vol. 16 (3), 2002, pp. 59-75.

[26] Krafft, M., Kundenbindung und Kundenwert, Physica, Heidelberg, 2002.

[27] V. Kumar, G. Ramani, and T. Bohling, "Customer Lifetime Approaches and Best Practice Applications", Journal of Interactive Marketing, Vol. 18 (3), 2004, pp. 60-72.

[28] Lumby, S. and C. Jones, Investment appraisal and financial decisions, Thomson Learning, London, 2001.

[29] Markowitz, H., Portfolio Selection: Efficient Diversification of Investments, John Wiley \& Sons, New York, 1959.

[30] R. M. Morgan, and S. D. Hunt, "The Commitment-Trust Theory of Relationship Marketing", Journal of Marketing, Vol. 58 (3), 1994, pp. 20-38.

[31] Rappaport, A., Creating Shareholder Value: A Guide for Managers and Investors, Free Press, New York, 1998.

[32] F. F. Reichheld and E. W. Sasser, "Zero Defections: Quality Comes to Service", Harvard Business Review, Vol. 68 (5), 1990, pp. 105-111.

[33] Reichheld, F. F. and T. Teal, The Loyalty Effect, Harvard Business School Press, Boston, Massachusetts, 1996.

[34] W. J. Reinartz, and V. Kumar, "On the Profitability of Long-Life Customers in a Noncontractual Setting: An Empirical Investigation and Implications for Marketing", Journal of Marketing, Vol. 64 (4), 2000, pp. 17-35.

[35] W. J. Reinartz and V. Kumar, "The Mismanagement of Customer Loyalty”, Harvard Business Review, Vol. 80 (7), 2002, pp. 86-94.
[36] Rust, R., K. Lemon, and D. Narayandads, Customer Equity Management, Prentice Hall, Englewood Cliffs, New Jersey, 2005.

[37] L. Ryals, "Measuring risk and returns in the customer portfolio", Journal of Database Marketing, Vol. 9 (3), 2001, pp. 219-227.

[38] L. Ryals, "Are your customers worth more than money?", Journal of Retailing and Consumer Services, Vol. 9 (5), 2002, pp. 241-251.

[39] L. Ryals, "Making customers pay: measuring and managing customer risk and returns", Journal of Strategic Marketing, Vol. 11 (3), 2003, pp. 165-175.

[40] D. C. Schmittlein, D. G. Morrison, and R. Colombo, "Counting your Customers: Who are they and what will they do next?”, Management Science, Vol. 33 (1), 1987, pp. 1-23.

[41] Schneeweiß, H., Entscheidungskriterien bei Risiko, Springer, Heidelberg, 1967.

[42] S. S. Scullin, J. Fjermestad, and N. C. Romano Jr., "Erelationship marketing: changes in traditional marketing as an outcome of electronic customer relationship management", Journal of Enterprise Information Management, Vol. 17 (6), 2004, pp. 410-415.

[43] J. Sheth, A. Parvatiyar, "Relationship in Consumer Markets: Antecedents and Consequences", Journal of the Academy of Marketing Science, Vol. 23 (4), 1995, pp. 255-271.

[44] R. Srivastava, S. Tasadduq, and L. Fahey, "Driving Shareholder Value: The Role of Marketing in Reducing Vulnerability and Volatility of Cash Flows", Journal of Market Focused Management, Vol. 2 (1), 1997, pp. 49-64.

[45] J. Strüker and S. Sackmann, "New Forms of Customer Communication: Concepts and Pilot Projects", Proceedings of the AMCIS, New York, USA, 2004.

[46] J. Strüker, S. Sackmann, and G. Müller, "Case Study on Retail Customer Communication Applying Ubiquitous Computing", Proceedings of the IEEE Conference on E-Commerce Technology 2004, San Diego, California, USA, 2004.

[47] J. Villanueva, P. Bhardwaj, S. Balasubramanian, and Y. Chen, "Managing Customer Relationships: Should Managers Really Focus on the Long Term?", Quantitative Marketing and Economics, Vol. 5 (2), 2007, pp. 99-129.

[48] R. Wayland, and P. Cole, "Turn Customer Service into Customer Profitability”, Management Review, Vol. 83 (7), 1994, pp. 22-24.

[49] Weber J. and M. Lissautzki, Kundenwertcontrolling, Wiley, Weinheim, 2005.

[50] Wedel, M. and W. Kamakura, Market Segmentation: Conceptual and Methodological Foundations, Kluwer, Dordrecht, Netherlands, 2000. 